\title{
La emigración como estrategia de escape a la represión social, política y económica de la dictadura franquista. El caso de los murcianos en Barcelona (1939-1950)
}

\author{
Miguel díAZ SÁNCHEZ \\ Universitat Autònoma de Barcelona (Espanya) \\ orcid.org/0000-0003-1896-4732
}

Presentació: 15 set. 2016 | Acceptació: 20 oct. 2016 | Publicació: 15 des. 2016

Citació recomanada: DíAZ SÁNCHEZ, Miguel. «La emigración como estrategia de escape a la represión social, política y económica de la dictadura franquista. El caso de los murcianos en Barcelona (1939-1950)». Franquisme \& Transició. Revista d'Història i de Cultura 4 (2016): 9-40. doi: http://dx.doi.org/10.7238/fit.voi4.3032

Resumen: Aprovechando las redes migratorias tejidas con anterioridad a la Guerra Civil, familias que sufrieron el asesinato, el exilio, la cárcel o la represión económica en la provincia de Murcia encontraron en la capital catalana un refugio en la inmediata posguerra. Se abordará el papel desarrollado por las mujeres de esas familias, el apoyo solidario que recibieron de los parientes emigrados con anterioridad, los medios de transporte utilizados y las dificultades que el Régimen franquista impuso para la libre circulación de personas. Palabras clave: Murcia, Barcelona, migraciones, represión, franquismo

\section{Migration as an escape strategy from social, political and economic repression under Francoism: The case of Murcians in Barcelona (1939-1950)}

Abstract: Taking advantage of migration networks made prior to the Spanish Civil War, families who suffered murder, exile, prison or economic repression in the province of Murcia found refuge in the Catalan capital immediately after the war. The role played by women from such families, the care and support received by relatives who had previously migrated, the means of transportation used and the difficulties imposed by the Franco regime on the free movement of people will be considered.

Keywords: Murcia, Barcelona, migrations, repression, Franco regime 


\section{Introducción}

El estudio historiográfico de un fenómeno social tan complejo como son las migraciones requiere la combinación de varios tipos de fuentes para acercarnos lo máximo posible a su comprensión. Es tradición abordar el análisis de las migraciones desde unas perspectivas macro que sepultan las historias individuales de los migrantes en un océano de cifras. En las últimas décadas, la utilización del marco teórico-metodológico proporcionado por la teoría de redes migratorias está proporcionado nuevas perspectivas al estudio de las migraciones del pasado (GARCÍA ABAD 2001; GURAK \& CACES 1998). La combinación de las perspectivas macro y micro (GULDi \& ARMitAGE 2016) que plantea y la diversificación de fuentes susceptibles de ser utilizadas, están favoreciendo el desarrollo de nuevos planteamientos que ayudan a una mejor comprensión de las migraciones interiores de nuestro pasado más reciente.

A través de los planteamientos teóricos y metodológicos desarrollados por Angelina Puig (1991) en la década de los noventa, este artículo pretende mostrar cómo Barcelona se constituyó en un lugar de destino para algunas familias murcianas tras finalizar la Guerra Civil. Aprovechando las redes migratorias tejidas con anterioridad al conflicto, familias que tuvieron que sufrir el asesinato, el exilio, la cárcel o la represión económica, encontraron en la capital catalana un refugio en la más inmediata posguerra. Mediante el testimonio de varios protagonistas de este proceso migratorio, se tratará el papel desarrollado por las mujeres de esas familias, el apoyo solidario que recibieron por parte de sus parientes emigrados con anterioridad, y cómo, gracias a esta combinación de factores, la cadena migratoria siguió contando con un extraordinario vigor en los años posteriores.

El artículo estará dividido en cuatro apartados, que abordarán sucesivamente: $(a)$ la constitución de la corriente migratoria entre la provincia de Murcia y el área metropolitana de Barcelona en las décadas anteriores al estallido de la Guerra Civil; $(b)$ la contextualización de lo realizado hasta el momento dentro del planteamiento teórico-metodológico que se utilizará para este estudio; (c) el tratamiento de la corriente migratoria desde un punto de vista cuantitativo a través del estudio de los saldos 
migratorios de la provincia de Murcia, y $(d)$ un último apartado en donde se otorgará especial importancia, entre otras cuestiones, a la memoria confeccionada por algunos protagonistas de la migración para las tres primeras etapas del proceso migratorio (toma de la decisión de emigrar, traslado al lugar de destino y asentamiento en él), dando importancia, también, a los canales de comunicación que mantuvieron abiertos con la provincia de Murcia.

\section{La constitución de la corriente migratoria}

Barcelona se constituyó, durante el primer tercio del siglo xx, en un foco de atracción para miles de familias, consecuencia de la pujanza en sus sectores secundario y terciario. No en vano, fue la primera ciudad del Estado español en alcanzar la cifra del millón de habitantes alrededor de 1930 (CABRÉ \& PUJAdes 1989).

Los territorios que mayor aporte demográfico proporcionaron a la capital catalana fueron en primer lugar, y en un proceso escalonado en el tiempo, la Cataluña rural, pasando después a los territorios limítrofes de Aragón y Valencia, para llegar finalmente a las provincias de Murcia y Almería, en el sudeste peninsular (OYón, MALDONADo \& GRIFUl 2001, 49-87). La corriente migratoria procedente del sudeste comenzó a tomar consistencia durante los años de la Primera Guerra Mundial, aunque su verdadero vigor se inició en la década del veinte (MARTínez CARRIón 2002, 109), una época en la que el hundimiento más que palpable del sector minero murciano había llegado a su cenit en las ciudades meridionales de la provincia (VILAR \& EGEA 1989, 315-317). Este hecho conllevó que muchos trabajadores de esta industria se unieran a una corriente ya iniciada y compuesta en su mayoría por murcianos del interior agrícola. Estos últimos habían visto cerrados sus canales emigratorios tradicionales a las colonias francesas del norte de África, clausurados a raíz del bloqueo marítimo alemán durante la Primera Guerra Mundial (Vilar et al. 1999, 50).

La corriente del interior agrícola tuvo presencia a lo largo de toda la costa mediterránea (incluida Francia), en una serie de tentativas que podrían calificarse como «movimientos pioneros», que con el tiempo aca- 
baron convirtiendo Barcelona y su área metropolitana en un destino exclusivo y definitivo cuando la crisis minera llegó a los municipios del sur murciano. Los factores principales de atracción hacia la capital catalana deben situarse en la política de obras públicas desarrollada por la dictadura primorriverista, así como en el auge de su industria y el de ciertas zonas mineras de su hinterland durante el transcurso de la Primera Guerra Mundial (Martínez Carrión 2005, 35 y 44; Bel Adell 1982, 101, 146 y 178; SUDRIÀ 1994).

\section{Una tarea necesaria y acuciante por realizar}

¿Por qué nos retrotraemos al periodo anterior a la Guerra Civil? La respuesta es sencilla: porque la corriente migratoria establecida con anterioridad al conflicto determinó gran parte de los movimientos que se produjeron en la década de los cuarenta entre las provincias de Murcia y Barcelona. O al menos es lo que se observa en los testimonios orales recogidos para confeccionar este trabajo. A diferencia de los migrantes procedentes de otros territorios durante la década de los cuarenta, los murcianos contaron con una experiencia anterior que facilitó, en cierta medida, su asentamiento en la Ciudad Condal. Nos referimos a la puesta en funcionamiento de mecanismos sujetos al establecimiento de redes migratorias: redes de parentesco, amistad y comunidad compartida (GURAK \& CACES 1998); unos condicionantes que facilitaron la continuidad del «mito» en el que se había convertido Barcelona en el imaginario migratorio de muchos murcianos durante la década de los veinte. Esa circunstancia incluso llegó a expresarse en la prensa de la época: «Para estos ya asentados aquí, o para los que allá suspiran por ello, Barcelona es siempre la tierra prometida» (FonTES 1946).

Como ya han puesto de manifiesto otros trabajos realizados con anterioridad, la parte relativa a la recopilación de testimonios orales, con el fin de obtener información de primera mano sobre este proceso migratorio, se hace acuciante por la edad de los protagonistas, ya que estos nacieron en su mayoría en las décadas de los veinte y de los treinta del pasado siglo (TudELA 2015). Es cierto que se puede acudir a las recopilaciones realizadas por otras investigaciones ligadas a los procesos migratorios 
que han tenido Cataluña como foco de atracción, pero, en la mayoría de casos, estas no tienen como eje principal de análisis las cuestiones que intentará abordar este trabajo (BотEY 1986; VILANOva 1996). Sin embargo, no sucede así con algunas autobiografías que nos han legado algunos murcianos que lograron adquirir cierta notoriedad dentro de la sociedad catalana y su tejido asociativo (CARRASCO 1994; Molina 2012; Mateos 1990 y 1993). También es factible acudir a los planteamientos metodológicos que nos ofrece el recurso de la posmemoria, aunque esta posibilidad está sujeta a la importancia otorgada a la emigración dentro de las trayectorias memorialísticas confeccionadas por las distintas familias (SARLO 2005, 125-157; QUíleZ 2014; HiRSCH 1997). Tampoco debemos obviar la importancia de las fuentes documentales para adquirir un mayor conocimiento sobre un proceso social tan complejo. Se trata de una dinámica migratoria que, por otro lado, no fue bien vista y tolerada por las autoridades franquistas en la inmediata posguerra, con el fin de ejecutar un mayor control social, político y económico sobre la población. Una cuestión, esta última, que ya fue puesta de manifiesto por Carme Molinero y Pere Ysàs (1987), y que ha sido magníficamente continuada por Martí Marín Corbera en los últimos años (2004, 2005a, 2005b y 2010a).

Por otro lado, y al igual que han puesto de manifiesto otros trabajos, es de vital importancia conectar las historiografías desarrolladas para la posguerra en los ámbitos locales, tanto en los territorios emigratorios como en los inmigratorios (PUIG 1991). En este aspecto, Murcia también ha contribuido, desde la investigación de ámbito local, al conocimiento de los mecanismos represivos del Régimen, especialmente de aquellos ligados al control social de la población y a la política económica desarrollada en Murcia dentro de los planteamientos de la autarquía (EsCUDERo 2000 y 2007; MARÍn GómEZ 2003). Sin embargo, la atención al fenómeno migratorio producido en la provincia durante la década de los cuarenta ha sido mínima, dado que ha aparecido tan solo en pequeñas referencias en las monografías desarrolladas para dicho periodo, tanto en las exclusivamente historiográficas como en las demográficas (BEN ADELL 1982, 146; VILAR et al. 1999, 25) y las dedicadas a la historia económica (MARTÍnEZ CARRIón 2002, 108-109; 2005, 45). Tan solo se referencia la década de los cuarenta como paréntesis entre los dos grandes periodos 
migratorios murcianos: los desarrollados en la década de los veinte y en las décadas de los cincuenta y sesenta del pasado siglo. Este abandono ha sido tradicional en todas las investigaciones desarrolladas a nivel estatal y no puede quedar justificado por más tiempo, especialmente cuando nos adentramos en los datos estadísticos que se tratarán en el siguiente apartado.

\section{La provincia de Murcia en el contexto emigratorio de la década de los cuarenta}

Abordar las migraciones desde un punto de vista estadístico durante este periodo es un ejercicio que debe tener en cuenta multitud de factores. El principal de ellos es el fenómeno del subregistro. Este factor toma especial relevancia sobre todo en los territorios que reciben inmigración, pero no tanto en aquellos territorios que expulsan individuos hacia otros lugares. Los saldos migratorios son la mejor fuente de información disponible para elaborar conclusiones a nivel macro, respecto a las migraciones producidas en un territorio durante una determinada cronología. El único problema a la hora de utilizarlos como principal fuente para analizar el periodo de la inmediata posguerra, es la imposibilidad de determinar hacia dónde se dirigieron los migrantes, especialmente en los casos de migración interior.

Multitud de trabajos han centrado su razón de ser en el cálculo de los saldos migratorios. En nuestro caso utilizaremos la clásica y pionera obra de Alfonso García Barbancho (1967) y la más reciente de Julio Alcaide Inchausti (2007), que, además de proporcionar datos sobre los saldos migratorios relativos a las migraciones dirigidas al exterior, revisa buena parte de los datos obtenidos por García Barbancho en la década de los sesenta.

La primera evidencia que se obtiene mediante la visualización de los datos es la primera posición, en términos negativos y absolutos, que ocupa la provincia de Murcia. Por lo tanto, el territorio murciano se convirtió en la principal cuenca emigratoria de España durante la década de los cuarenta, aunque, como podemos ver en la siguiente gráfica, lo hace en números similares a las provincias que le siguieron: Orense, Jaén y Almería. 


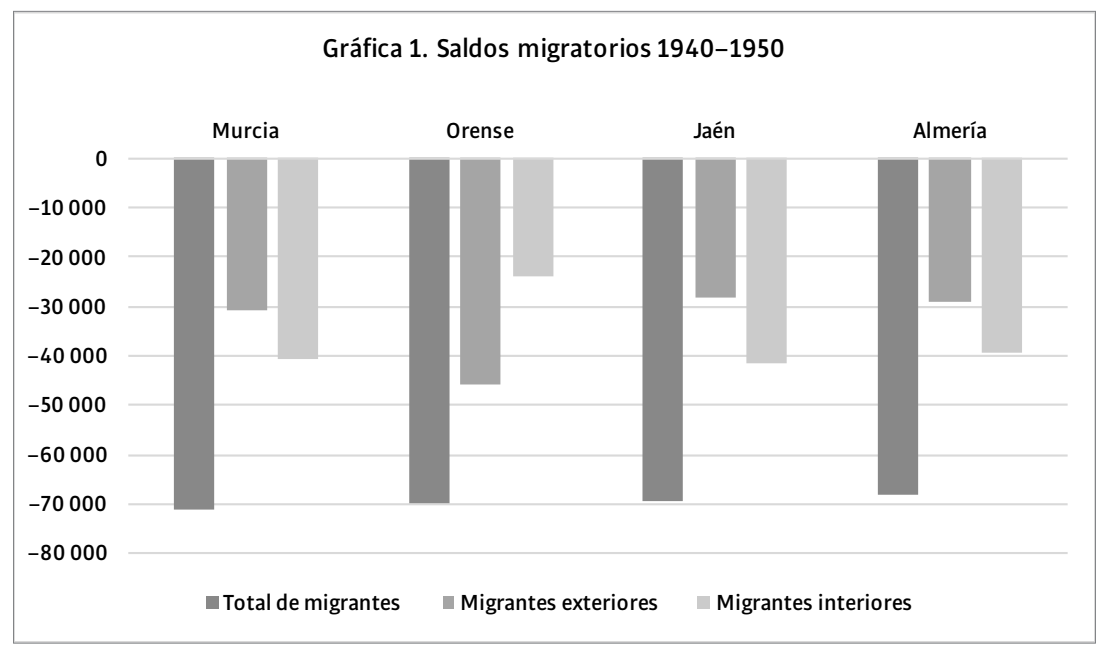

Fuente: elaboración propia a partir de los datos de Julio Alcaide Inchausti.

Por quinquenios, Murcia ofrece, durante el periodo 1940-1945, un saldo migratorio negativo de -4085 en relación con el exterior de España. Para el quinquenio $1945^{-1950}$ lo hace en -26673 . Para el primer periodo, es la provincia que presenta el saldo migratorio negativo más alto de España; la segunda es Almería, con -3 116. En el caso del segundo quinquenio, solo fue superada por Orense ( -47601$)$, y la siguieron de cerca Almería (-25 861) y Jaén (-25 167). Son relativamente importantes los datos del primer quinquenio, ya que nos podrían indicar un exilio político posterior al inmediato final de la Guerra Civil, mucho mayor del que se pensaba hasta ahora, en las provincias del sudeste peninsular (Murcia y Almería), sobre todo teniendo en cuenta las dificultades implícitas a la situación geográfica de las dos provincias en comparación con otras zonas de España que disponían de frontera terrestre con otros países, especialmente Francia (GONZÁlez, EsCUdERo \& ANDÚJAR 2015; VILAR 2008). Para el caso de las migraciones interiores (las dirigidas a otras provincias españolas), la provincia de Murcia ofrece un saldo negativo de -16 199 para el quinquenio 1940-1945 y -24 238 para el de 1945-1950. En el primer periodo solo fue superada por Lugo (-6o 184), Jaén (-19 384) y Almería (-16 474). En el caso del quinquenio 1945-1950, y al igual que suce- 
de con el saldo relativo al exterior, únicamente fue superada por Orense (-45 981), y la siguieron de cerca Almería (-22 820) y Jaén (-22 015).

Por otro lado y como podemos visualizar en la gráfica 2, el saldo migratorio resultante en la provincia de Murcia durante la década de los cuarenta fue el segundo en importancia durante la primera mitad del siglo xx. Solo fue superado por el producido en la década de los veinte, periodo en el que existe un gran consenso entre los distintos autores para fijar el inicio del verdadero «éxodo murciano», a raíz del declive absoluto de sus cuencas mineras. Sin embargo, el indicador más llamativo que muestra la gráfica es la preponderancia de la década de los cuarenta sobre la de los cincuenta en lo relativo a las migraciones interiores, ya que rompería con la tradicional visión general de la cronología migratoria interna de la época franquista, al menos en lo que a la provincia de Murcia se refiere, al mostrarnos una dinámica que situaría el inicio de las migraciones a gran escala en la década de los cuarenta y no en la de los cincuenta. Esta situación coincide con la de la provincia de Almería, otro territorio que compartió el área metropolitana de Barcelona como lugar de emigración preponderante durante el periodo de entreguerras. Un hecho, pues, que nos empuja a llegar, para el caso almeriense, a unas conclusiones similares a las que se irán relatando para el caso murciano. No en vano, dichos territorios tuvieron en común multitud de factores socioeconómicos, especialmente los ligados a la industria minera, con continuos trasvases de población entre las dos provincias hasta la llegada de la crisis minera en la tercera década del siglo xx (MArTínez Soto et al. 2008). Tal y como podemos observar en las siguientes gráficas, las dos provincias comparten la expresión de sus dinámicas migratorias durante la primera mitad del siglo xx: una importante migración durante el periodo de entreguerras, un considerable descenso durante la década de los treinta (que muy probablemente esté ligado a las expectativas favorables que ofreció el régimen republicano) y un repunte considerable durante la inmediata posguerra (CAPEL 1963, 117). 


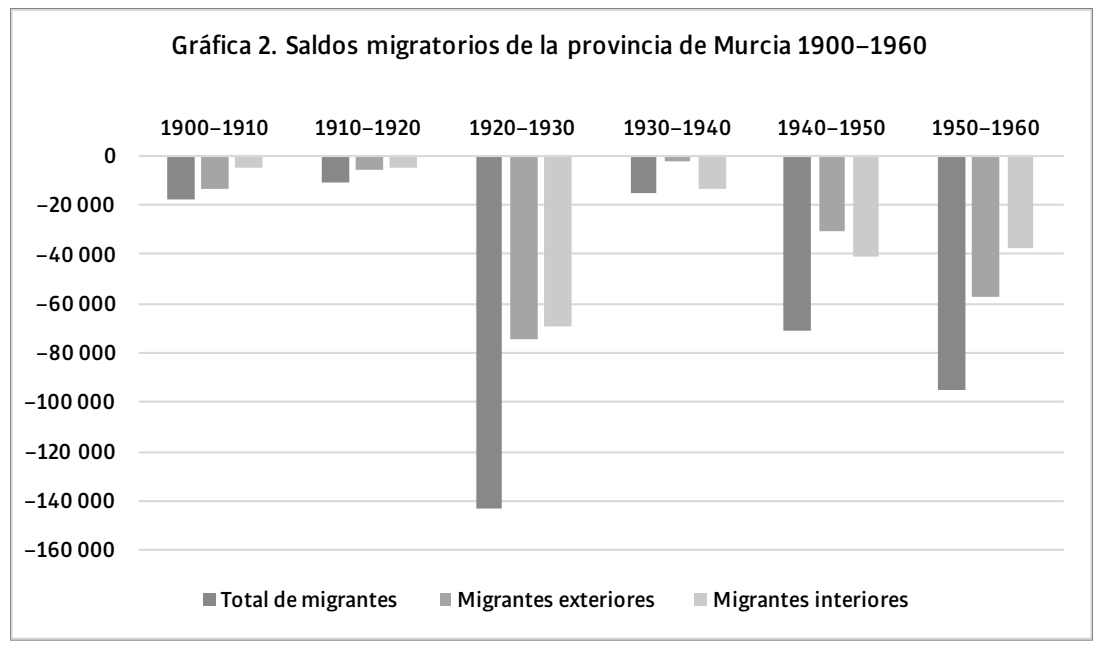

Fuente: elaboración propia a partir de los datos de Julio Alcaide Inchausti.

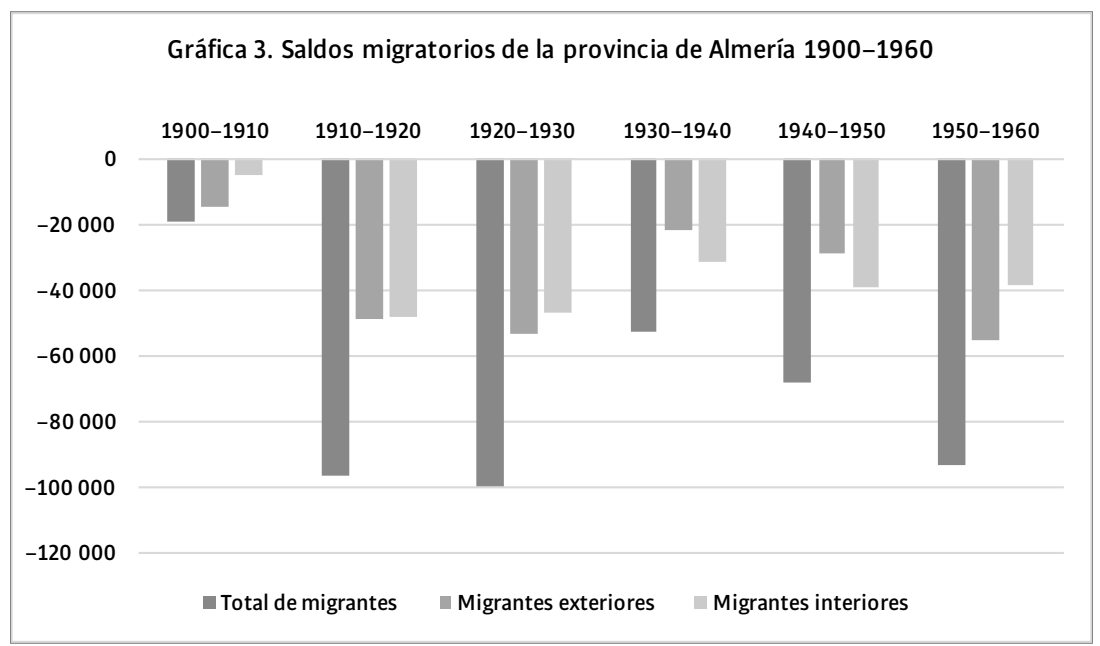

Fuente: elaboración propia a partir de los datos de Julio Alcaide Inchausti.

Volviendo al análisis exclusivo de la provincia de Murcia, también podemos observar en las gráficas 4 y 5 cómo el saldo migratorio hacia el exterior es ligeramente superior al del interior en el quinquenio 19451950. También es relevante que, para el mismo quinquenio, sean mayoritariamente mujeres las que emprenden la emigración, dado que doblan el dato que resulta para la emigración masculina. Sin embargo, en el pri- 
mer quinquenio, la emigración masculina interior sí que es ampliamente superior a la de las mujeres, pero no es así en el caso de la exterior, que es tan solo ligeramente superior.

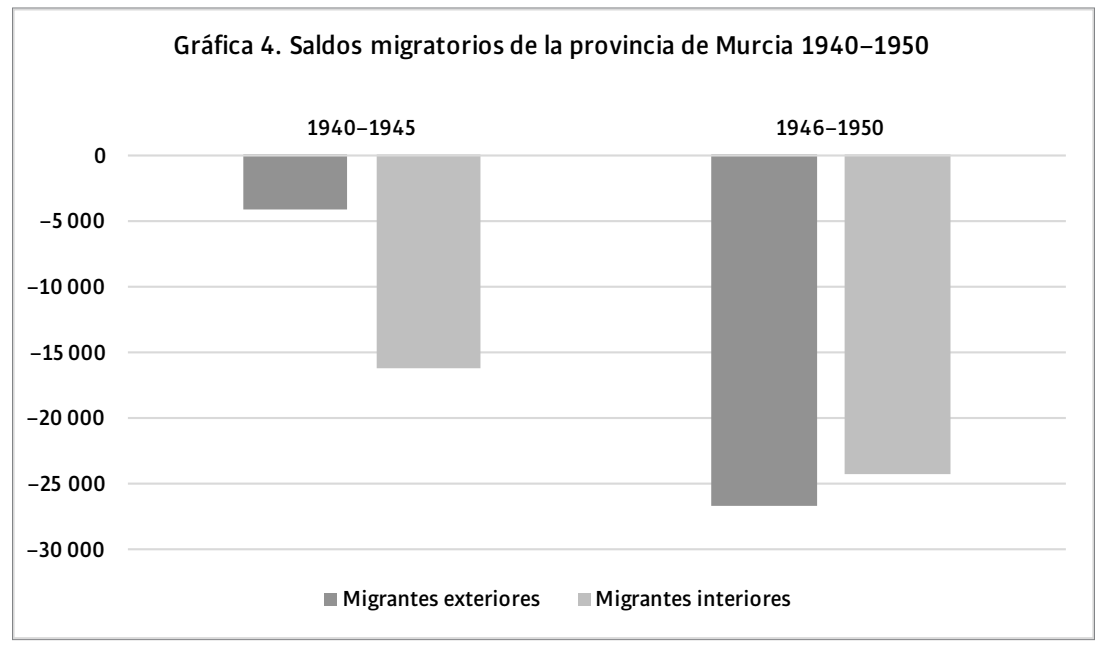

Fuente: elaboración propia a partir de los datos de Julio Alcaide Inchausti.

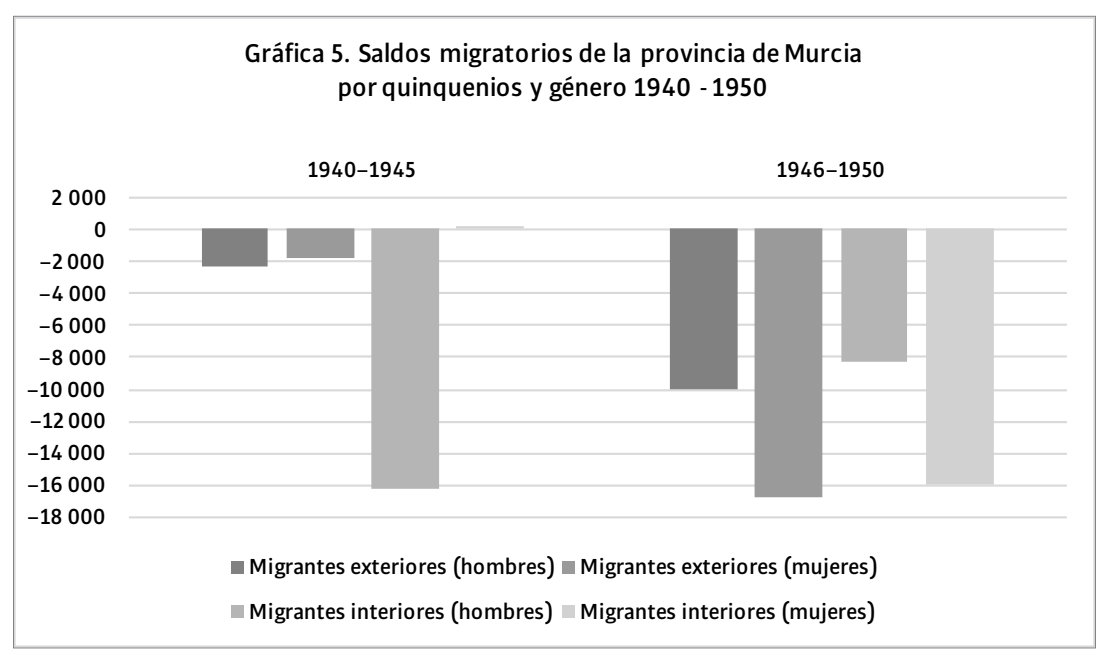

Fuente: elaboración propia a partir de los datos de Julio Alcaide Inchausti. 
El saldo exterior es factible que aumente debido al restablecimiento, en 1946, de la ley de 1924 que autorizaba la libre circulación de personas hacia el exterior (aunque en unos términos aún muy restrictivos). ${ }^{1} \mathrm{~A}$ esto se unió que los países sudamericanos suspendieran las políticas inmigratorias restrictivas que aplicaban desde la crisis de los años treinta (Ben Adell 1982, 197; PUyol 1979, 44-45). Es posible que muchos murcianos y murcianas aprovecharan también los canales migratorios abiertos con Sudamérica y Argelia antes de la Guerra Civil (VIlar et al. 1999, $62,81,107$ y 118).

Desde una perspectiva de género, se observa una emigración interior realizada predominantemente por hombres durante el primer quinquenio; sin embargo, las mujeres doblan en número de efectivos a los hombres durante el segundo. A primera vista parece indicar que las familias eligieron una estrategia migratoria a ejecutar en escala, en la cual los hombres serían los encargados de realizar el movimiento pionero para ser seguidos posteriormente por las mujeres de las unidades familiares. Es posible también que esta estrategia migratoria individual cobre sentido como mecanismo de «emigración clandestina» utilizado por las familias con el fin de eludir el control que el Régimen impuso a la libre circulación de personas durante el primer quinquenio de la década. Una emigración clandestina que no solo se circunscribió a la realizada dentro de las fronteras del Estado español, sino también hacia otros países, mediante la utilización de innumerables estrategias para la evasión, que, además de contar con extraordinarias similitudes con las que se realizan en el presente (aunque en sentido inverso), fueron conocidas por las autoridades de la dictadura, e intentaron además ponerles freno, al menos en los territorios del arco mediterráneo español:

Las observaciones hechas y gestiones realizadas por personal de esta Brigada, señalan la facilidad que encuentran en gran número de gentes para abandonar clandestinamente el territorio nacional, de modo especial las que se dirigen a Francia y el Marruecos Francés. Últimamente se ha sabido que de Elche y zonas cercanas, se ausentaron varias personas y aún familias, que en princi-

1 Orden del Ministerio de Trabajo de 29 de marzo de 1946, BOE 99 (9 abr. 1946). 
pio se dirigen a Palma de Mallorca donde, al parecer, encuentran lanchas de pesca que se encargan de trasladarlas a territorio francés mediante el abono de una cantidad de dinero. ${ }^{2}$

También es posible que detrás de la preponderancia de los hombres puedan jugar un factor importante los innumerables movimientos producidos tras la finalización del conflicto: soldados movilizados por los dos bandos, traslados penitenciarios y destierros. Sin embargo, bien es cierto que probablemente estas personas no estuvieran contabilizadas en los censos de población (Molinero, Sala \& Sobrequés 2003; Gómez Bravo 2009; Prada Rodríguez 2010). Por otra parte, también es necesario tener en cuenta la vuelta a sus localidades de origen de los miles de refugiados producidos por la Guerra Civil, aunque, en este aspecto, las diferencias entre los que salieron de Murcia y los que entraron en ella bajo esta condición no debieron de ser considerables. Se trata, pues, de unos movimientos de personas que también se produjeron entre las provincias de Murcia y Barcelona, tal y como muestran algunas fuentes documentales. ${ }^{3}$ A pesar de estas evidencias documentales y de la falta de una investigación concienzuda sobre esta temática en la provincia de Murcia, todo parece indicar que los territorios que más acogidos aportaron fueron Madrid, La Mancha y la zona andaluza ocupada por los sublevados (De Silva 1978).

Retomando la cuestión de género, los testimonios recogidos para la elaboración de este trabajo otorgan una mayor importancia al papel desempeñado por las mujeres en la constitución de las redes migratorias que se establecieron entre Murcia y Barcelona. Aunque es cierto que en muchos casos la emigración dependió de unas estrategias familiares en donde el rol decisorio de las mujeres fue secundario, fueron ellas

2 «Informes nacionales con carácter socio-político emitidos quincenalmente por el Servicio de Información de la Dirección General de Seguridad y la Brigada de Información Policial de Alicante» (2 dic. 1948), Gobierno Civil, Secretaría General, GC-Go2578.oo, Archivo Histórico Provincial de Alicante.

3 La Vanguardia, 19 abr. 1939, 5. «Correspondencia de la Secretaría de Orden Público con el Cuerpo de Seguridad y Asalto, la Guardia Civil y la Jefatura de Fuerzas de la Policía Armada» (4 abr. 1940), GOB, 6570/12, Archivo Histórico Provincial de Murcia. 
las que más canales abiertos mantuvieron con los pueblos de origen, de modo que se convirtieron en las principales transmisoras de información hacia dichos pueblos, lo que conllevó que también fueran ellas las que en buena medida consiguieran trabajo y posibilidades de asentamiento a nuevos emigrantes (BORDERÍAS 1993). ${ }^{4}$

Es evidente que la colonia murciana instalada en Barcelona con anterioridad a la Guerra Civil desempeñó un papel fundamental en la llegada de los migrantes posteriores al conflicto. Lo que es más difícil de contrastar y ubicar correctamente en términos cuantitativos es el porcentaje de murcianos y murcianas que decidieron instalarse en el área metropolitana de Barcelona durante los primeros años de la dictadura. Un acercamiento lo más preciso posible se puede lograr mediante el análisis de las fuentes confeccionadas nominalmente, especialmente a través de los padrones de habitantes elaborados durante este periodo. Pero aún nos enfrentamos a la problemática que supone el subregistro en esta época, ya mencionado anteriormente. A pesar de esta problemática, algunas investigaciones confeccionadas hasta la fecha, y siguiendo este patrón de análisis nominal, nos muestran la importancia de Barcelona y sus alrededores en las dinámicas migratorias de los murcianos durante los años cuarenta. Una de estas investigaciones es la llevada a cabo por Martí Marín Corbera (2006) para el caso de Sabadell. En ella sitúa a los murcianos como la primera colonia no catalana en importancia en los establecimientos inmigratorios de la ciudad, dentro de la cronología a la que nos ceñimos. Por otro lado, y desde un estudio centrado en la localidad murciana de Águilas, Pedro Morata pudo deducir el número de habitantes de esta localidad que decidió emigrar a Barcelona. Lo logró gracias al especial celo del funcionariado del ayuntamiento en la anotación de los destinos de cada emigrante en las hojas padronales del quinquenio 1945-1950, algo que, por otra parte, era poco habitual en la cronología que nos ocupa. Según estas indicaciones, un tercio de los emigrantes aguileños durante el periodo señalado habría elegido Barcelona como

4 Disponemos de documentación que mostraría la iniciativa personal de algunas mujeres, al solicitar ayuda económica a la Diputación con el fin de emprender la emigración a Barcelona: «Libros de Actas de Sesiones de la Diputación Provincial de Murcia» (28 en. 1949), DIP 22/1 f. 116r, Archivo Histórico Provincial de Murcia.

FRANQUISME \& TRANSICIÓ 4 (2016) ISSN 2014-511X PUNCTUM, UNIVERSITAT OBERTA DE CATALUNYA \& FUNDACIÓ CARLES PII SUNYER 
destino (MORATA 2008, 280-281). Se trata de una cifra nada despreciable, y que probablemente tenga mucho que ver con el aprovechamiento de la tradición migratoria existente entre las dos zonas por parte de los migrantes en las décadas de 1920 i 1930.

Y, para finalizar este apartado, también es necesario dotar de importancia a un par de cuestiones que hemos observado en los primeros acercamientos a este tipo de fuentes. Nos referimos a la necesidad de realizar un seguimiento nominativo por las principales zonas en donde se desarrollaron núcleos de infraviviendas (el denominado «barraquismo») en la capital catalana; lugares que fueron focos tradicionales de asentamiento para la inmigración reciente en la ciudad (ECHENIQUE 1965, 26-27; OYón \& IGLESIAS 2010, 32-33), que se convirtieron en años posteriores en uno de los problemas más acuciantes para las autoridades gubernativas, las cuales optaron incluso, para su resolución, por las deportaciones masivas de migrantes a sus lugares de procedencia (TÉBAR et al. 2015, 150-169). La segunda cuestión se ciñe a la importancia que pudieron adquirir las mujeres que quedaron en situación de viudedad durante el conflicto, ya que los padrones municipales de Barcelona confeccionados durante la década de los cuarenta nos indican su papel preponderante como iniciadoras de cadenas migratorias dirigidas hacia sus lugares de nacimiento, especialmente entre los familiares de segundo grado. Es una dinámica que podría responder a estrategias migratorias y familiares destinadas al apoyo mutuo para hacer frente a las dificultades de la posguerra, tanto en ámbitos urbanos como rurales.

\section{Las migraciones murcianas a Barcelona a través de los relatos (1940-1950)}

En el último apartado se abordará el relato migratorio confeccionado por seis testimonios que son ilustrativos de diferentes tipos de migración durante el periodo 1940-1950. Tomaremos especial interés en la trasmisión que los protagonistas de la migración realizan sobre las tres etapas iniciales que aparecen en todo proceso migratorio: toma de decisión para emprender la migración, traslado y asentamiento en el destino. Hay que tener en cuenta, además, que hablamos de migraciones produ- 
cidas en buena medida por la situación política, social y económica de España durante la inmediata posguerra: represión, exilio, cárcel y precariedad económica.

\subsection{La opción migratoria como «derecho de fuga» de los vencidos}

Fue Martí Marín Corbera $(2006,142)$ el que introdujo los conceptos «derecho de fuga» $\mathrm{y}$ "grado cero de la revuelta» para analizar las causas de las migraciones internas durante los primeros años de la dictadura. En muchos casos no se debería descartar la decisión de muchas personas para emprender la migración como medio de resistencia pasiva para huir o escapar del control social impuesto por el Régimen franquista a las familias que habían tenido dentro de su seno a algún miembro involucrado con la causa republicana y los movimientos obreristas durante el periodo republicano y la Guerra Civil:

El motivo de nuestra emigración a Barcelona fue la Guerra Civil, a los pocos días del asesinato de mi padre. Mi padre fue un dirigente destacado de la CNT de Mazarrón [...] Cuando acabó la guerra lo capturaron y los falangistas se cebaron con él: lo condenaron a muerte junto a cinco compañeros y lo fusilaron el 9 de febrero de 1940 [...] a mi madre le quitaron la casa, el dinero, todo el dinero que tenía, lo entregaron al Ayuntamiento, nos quitaron todo, todo lo que teníamos. Ante este hecho mi madre se rebeló y al rebelarse pues eso, pasó a ser una mujer marcada por los falangistas y también querían darle el paseo. Entonces, gracias a un tío suyo que era de derechas, nos vino a buscar para llevarnos a Chinchilla y allí cogimos un tren hasta Barcelona. ${ }^{5}$

Cuando terminó la guerra mi padre tuvo que marchar al exilio, a Orán; mi madre se quedó sola con cuatro hijos pequeños que alimentar. Mi padre tuvo que irse porque era delegado de abastos y miembro del Frente Popular de Águilas como representante de la UGT, era ferroviario y socialista, y en aquellos momentos le tocó defender su papel [...] Mi madre se tuvo que tirar al estraperlo cuando se gastó lo poco que tenía, pero empezaron a acosarla con

5 Entrevista realizada a Arnaldo Tovar Muñoz (7 de noviembre de 2014).

FRANQUISME \& TRANSICIÓ 4 (2016) ISSN 2014-511X PUNCTUM, UNIVERSITAT OBERTA DE CATALUNYA \& FUNDACIÓ CARLES PI I SUNYER 
multas y estancias en el cuartelillo, la obligaron incluso a cambiar el nombre a uno de mis hermanos. Finalmente decidió venir a Barcelona en $1942{ }^{6}$

Obviamente nos encontramos ante dos situaciones excepcionales dentro de las complejidades intrínsecas a cualquier proceso migratorio. Lo predominante en los relatos son las motivaciones económicas en la decisión para emprender la emigración. No en vano, la situación calamitosa en la que quedó la provincia murciana es abundantemente indicada en las distintas recopilaciones orales que se han realizado para analizar este periodo (EsCUdERo 2000, 172-198; MARÍn GómEZ 2003, 149-163). A esto habría que añadir la recuperación de las estructuras jerárquicas dominantes en cuanto a las relaciones laborales que dominaron el agro murciano en el periodo anterior a la Segunda República (NicolÁs MARÍN 1988); una situación que, sin lugar a dudas, también fue determinante para que muchas personas acogieran la idea de emigrar como la mejor de las salidas posibles:

Mi padre llegó antes que mi madre, en 1949, pero él ya había estado antes en Barcelona durante la Guerra Civil [...] Las familias de mi padre y mi madre eran pobres, jornaleros en el campo de Archena [...] Su decisión de emigrar se fundamentó en las motivaciones económicas. No podían vivir del jornal que les proporcionaban sus trabajos en la huerta y, cuando mi madre se quedó embarazada de mí, decidieron salir de allí porque su situación económica se transformó en insostenible y Archena ya no daba ninguna posibilidad ¡El caciquismo hacía la vida imposible en el pueblo! Recuerdo que mi padre decía en muchas ocasiones esta sentencia. ${ }^{7}$

Sin embargo, los dos primeros testimonios citados inciden en la idea ya expuesta por Angelina Puig respecto a la exclusiva utilización de las motivaciones económicas para explicar los canales migratorios que tuvieron Barcelona como principal destino en la posguerra. En Murcia, además, toma especial cuerpo la posibilidad de utilizar la migración como

6 Entrevista realizada a Juan Navarro García (11 de noviembre de 2014).

7 Entrevista realizada a José Molina Ayala (3o de octubre de 2014).

FRANQUISME \& TRANSICIÓ 4 (2016) ISSN 2014-511X PUNCTUM, UNIVERSITAT OBERTA DE CATALUNYA \& FUNDACIÓ CARLES PI I SUNYER 
medio de resistencia pasiva. No en vano fue de las pocas provincias que no desarrollaron movimientos de resistencia interna contra la dictadura (EsCUdero 2007, 112; MARÍn JOVER 1987; TiERnO GALVÁN 1982, 147-179). Por lo tanto, el factor de la guerrilla (o cualquier otro tipo de oposición) como elemento no exclusivamente económico no fue determinante en la toma de decisión para el caso de Murcia, aunque sí fue el caso en otras provincias limítrofes que desarrollaron un alto grado de resistencia guerrillera (TUDELA 2015, 5855-5856). Por otra parte, en varios expedientes producidos por la Junta Provincial de Libertad Vigilada de Murcia se especifica la elección de Barcelona por parte de algunos presos (y presas) como ciudad para cumplir el destierro al que fueron condenados. En dichos expedientes se especifica la presencia de familiares de los penados en Barcelona como motivo de la elección de dicha ciudad, en lo que sería una muestra palpable de la utilización de los canales migratorios abiertos con anterioridad al conflicto. ${ }^{8}$ Aunque, sorprendentemente, las autoridades penitenciarias aprobaron un número destacado de peticiones a pesar de que el Régimen puso especial interés en dificultar los traslados de los beneficiarios de la libertad vigilada a las grandes ciudades:

Para residir en Madrid, Barcelona, Valencia, Sevilla y Zaragoza. Las Juntas examinarán cuidadosamente las solicitudes para residir en tales ciudades superpobladas y sólo elevarán propuesta cuando el expediente dé motivos muy calificados en el solicitante. Si éste manifiesta que vivía en cualquiera de dichas ciudades el día 18 de julio de 1936, deberá acompañar el documento correspondiente, además del contrato de trabajo que llevará el visado del Sindicato en que profesionalmente esté encuadrado o, en su caso, el de la Oficina de Colocación o de la Delegación de Trabajo. ${ }^{9}$

A los requisitos burocráticos hay que unir las dificultades que ocasionó, a aquellos que pretendieron asentarse en Barcelona, la destrucción del

8 «Expedientes de libertad condicional de Totana (1941-1955)», Prisiones, 1609; y «Autorizaciones de traslado de residencia», Prisiones, 1393/3, Archivo Histórico Provincial de Murcia.

9 «Circular número 25 de la Subdirección General de Libertad Vigilada con instrucciones para las Juntas Locales, según acuerdo de la Comisión Central», Archivo Histórico Provincial de Murcia; Boletín Oficial de Murcia (20 sept. 1944): 1665, AMB, 1147/5. 
padrón de habitantes elaborado a finales de 1935 en uno de los múltiples bombardeos que sufrió la ciudad durante la Guerra Civil. Este hecho dificultó a muchos solicitantes demostrar arraigo en la capital catalana, al menos, durante el periodo republicano. Aunque esta es tan solo una más de las dificultades a las que hubieron de hacer frente todas las personas que decidieron emigrar durante la década de los cuarenta con el fin de probar fortuna en otros lugares distintos al de su residencia cuando finalizó la Guerra Civil. En el siguiente apartado se abordará buena parte de los requisitos burocráticos que la población hubo de cumplir si su opción para prosperar se fundamentó en la emigración, al menos mediante los cauces legales diseñados por la dictadura.

\subsection{El viaje}

La cuestión del traslado suele quedar apartada de los análisis migratorios. Para el caso que nos ocupa, Ivan Bordetas (2009) ya puso de manifiesto la necesidad de atender a esta cuestión, más aún cuando nos encontramos dentro de un periodo cronológico en el que la libertad de movimientos dentro de las fronteras de España estaba especialmente condicionada por los mecanismos de control social impuestos por la dictadura.

Las fuentes orales disponibles hasta el momento nos indican que los medios de transporte utilizados por los murcianos fueron principalmente el ferrocarril y, en menor medida, el transporte marítimo. Como es obvio, el medio de transporte utilizado dependió sobre todo de la situación geográfica de las localidades de origen de los migrantes y de las combinaciones que ofrecían las empresas transportistas. Es relevante el caso de los migrantes procedentes de Águilas, ya que todos los testimonios recogidos hasta la fecha mencionan, como medio utilizado para desplazarse a Barcelona durante la década de los cuarenta, un pequeño barco de transporte de mercancías y pasajeros llamado María Ramos, un nombre que ha quedado marcado en la memoria de todos los migrantes aguileños instalados en Barcelona durante el periodo republicano y la inmediata posguerra: 
En el María Ramos me tiré tres días. ¡Que mareos! Y recuerdo que decían ¡Ya se ve Colón! ¡Ya se ve Colón! Y yo no veía nada. ¡Tres horas y pico! Llegamos a media tarde, mi madre me estaba esperando y mi hermano, también; ellos también vinieron en este barco dos años antes que yo, en 1942 [...] ¡Pequeñísimo! ¡Era un cascarón pequeñísimo! Iba de cabotaje [...] me metieron en el camarote, en donde me puso el mayordomo, un hombre que había hablado con mi tío para que me cuidara [...] el barco llegaba de Almería y antes, de Málaga, pasaba después a Águilas, de Águilas a Cartagena y de allí ya venía a Barcelona. ${ }^{10}$

Mis hermanas llegaron a Barcelona antes que yo para servir en una casa, a finales de los cuarenta. Vinieron en un barco que hacía el trayecto Málaga-Barcelona y se llamaba María Ramos, de la naviera Ramos, que estaba aquí en Barcelona. Paraba también en Valencia y Alicante. Un viaje que duraba unos tres días. ${ }^{11}$

Mis padres y hermanos mayores vinieron en 1928 y lo hicieron en el María Ramos. Mi padre vino para trabajar en las obras del metro y mi madre cosía camisas por su cuenta. Mi madre iba muchas veces a Águilas, mi padre menos, pero mi madre siempre lo hacía en este barco. Recuerdo que decía que tardaba dos o tres días en hacer el trayecto [...] Volvieron todos a Águilas en 1932, pero en 1948 volvieron a Barcelona, y los primeros viajes de mi padre antes de que volviéramos todos los hizo en el María Ramos [...] El María Ramos acabó hundiéndose en el puerto de Barcelona. No recuerdo la fecha exacta. Sería a mediados de los cincuenta. Era un barco muy viejo. ${ }^{12}$

Los emigrantes que veníamos de Ceuta y de la costa mediterránea andaluza y murciana, viajábamos en un barco de servicio regular llamado «María Ramos» [...] Nosotros lo llamábamos el Éxodo porque en él se viajaba en las mismas condiciones que en ese barco históricamente famoso y conocido con el mismo nombre [...] Tardaba entre dos y tres días en hacer el trayecto desde Águilas a Barcelona. (CARRASCO 1994, 124)

10 Entrevista realizada a Juan Navarro García (11 de noviembre de 2014).

11 Entrevista realizada a José Sánchez González (4 de noviembre de 2014).

12 Entrevista realizada a José María Hernández Martínez (7 de abril de 2015). 
Pero, como hemos indicado con anterioridad, el medio de transporte preferencial utilizado por los murcianos fue el ferrocarril. Se trataba de un viaje que también contó con dificultades para su realización, especialmente por los distintos transbordos que se tenían que llevar a cabo antes de llegar a Barcelona y los continuos retrasos de las empresas transportistas, especialmente aquellas ligadas al sector ferroviario:

Bueno, yo era muy pequeñito, tenía seis años. No me acuerdo de todo, pero recuerdo algunas cosas. Recuerdo cómo estábamos en la estación de Chinchilla. Recuerdo a mi madre preocupada por el tren que tenía que coger para venir a Barcelona. Recuerdo un frío espantoso por culpa de la ropa que llevábamos. Estaba otra tía mía que también vino y que su marido estaba en el campo de concentración de Argelès, en Francia, estaba exiliado [...] fueron bastantes los días que tardamos en llegar a Barcelona y con mucha hambre, mucha hambre porque desgraciadamente mi madre y mi tía llevaban muy poca comida para el viaje y pasamos mucha hambre en el tren. ${ }^{13}$

Nosotros vinimos en 1947, en el tren, y los muebles de la casa llegaron en barco un par de meses después. Un tren que por aquel entonces tenía los asientos de madera, e iba tan lleno de gente, que algunos de nosotros tuvimos que quedarnos en los pasillos. La única que pudo sentarse fue mi madre, y el resto, sentados sobre las maletas en el pasillo, porque no había sitio para nosotros. ${ }^{14}$

Aunque el mejor relato respecto a las lamentables condiciones que tuvieron que soportar los migrantes que utilizaron el servicio de ferrocarril para desplazarse a Barcelona durante la década de los cuarenta, nos lo ofrecen los funcionarios de la Dirección General de Ferrocarriles en Alicante:

En las tres líneas que llegan a esta capital se aprecia y comentan desfavorablemente por los usuarios notorias deficiencias, especialmente en las de Andaluces y Secundarios. En la primera de ellas resultan los desplazamientos incó-

13 Entrevista realizada a Arnaldo Tovar Muñoz (7 de noviembre de 2014).

14 Entrevista realizada a Fernando Martínez (10 de noviembre de 2014). 
modos: numerosos departamentos de los coches de viajeros van, a veces sin iluminación, con los cristales y las ventanillas rotos y se han oído quejas sobre la existencia de parásitos. Los viajeros observan una conducta incorrecta, invadiendo los coches, aunque no correspondan a la clase de su billete e introduciendo sacas y bultos de gran tamaño, sin que los revisores hagan nada por evitarlo o corregirlo. ${ }^{15}$

Los viajeros que utilizan el correo que hace este servicio regular entre Granada y Alicante, se quejan del estado deplorable de los coches, tanto de $1 .{ }^{\mathrm{a}}$ como de $3 .{ }^{a}$ clase. Se ha comprobado, efectivamente, que estos coches se hallan algunos faltos de cristales y cortinillas en las ventanas y carecen además, de las condiciones de higiene más elementales; no solo se censura este abandono, sino también la velocidad del convoy, resultado del deficiente estado de las locomotoras. ${ }^{16}$

A esto hay que añadir, tal y como algunas fuentes documentales muestran, la gestación de un mercado negro en la adquisición de billetes de larga distancia, de modo que se extrapolaba el estraperlo que funcionó en todos los aspectos de la sociedad española de esta época:

Son muchas las quejas que se oyen de viajeros que no pueden conseguir billetes de larga distancia ni aún con ocho días de anticipación y en cambio se habla de otros muchos que lo consiguen al día, de cualquier clase, pero median-

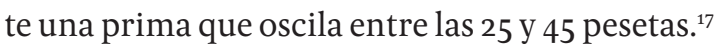

15 «Solicitando de la Dirección General de Ferrocarriles la modificación de los servicios de esta capital» (1 may. 1947), Gobierno Civil, Secretaría General, GC-Go2573.oo1, Archivo Histórico Provincial de Alicante.

16 «Informes nacionales con carácter socio-político emitidos quincenalmente por el Servicio de Información de la Dirección General de Seguridad y la Brigada de Información Policial de Alicante» (2 dic. 1948), Gobierno Civil, Secretaría General, GC-Go2578.001, Archivo Histórico Provincial de Alicante.

17 «Informes nacionales con carácter socio-político emitidos quincenalmente por el Servicio de Información de la Dirección General de Seguridad y la Brigada de Información Policial de Alicante» (12 sept. 1944), Gobierno Civil, Secretaría General, GC-Go3453.001, carpeta «Partes», Archivo Histórico Provincial de Alicante. 
Se han observado quejas relativas a las grandes dificultades que hay que vencer en esta capital para la adquisición de billetes del ferrocarril de largo trayecto, quejándose los viajeros de que los billetes los acaparan unos cuantos individuos, siempre los mismos, que ocupan los primeros puestos en las colas, especialmente en las oficinas de RENFE, para después cobrar de prima de 25 a 50 pesetas. ${ }^{18}$

Aunque, en los relatos orales recogidos hasta el momento, no se evidencian muchas dificultades ajenas a las expuestas en los testimonios anteriores, el Régimen puso especial interés en tener el mayor conocimiento posible respecto a los movimientos que las personas realizaban por todo el levante sin atenerse a las exigencias burocráticas (salvoconductos, tarjetas de identidad, etc.) que la dictadura exigió, contraviniendo, dicho sea de paso, el artículo 14 del Fuero de los Españoles, en el que se especificaba el derecho de los españoles a fijar libremente su lugar de residencia. Este celo fue especialmente desarrollado por parte de la Dirección General de Seguridad:

Frecuentemente el caso de ser entregadas en las Comisarias o Inspecciones del Cuerpo General de Policía correspondientes [Alicante] personas que son detenidas por los funcionarios de ferrocarriles a causa de ser halladas sin documentación u ofrecer sospechas de diversa índole, para que por la Dependencia respectiva sean ingresadas en prisión donde permanecen como detenidos gubernativos si no hay méritos para ponerlos a disposición de otra Autoridad, mientras se tramita la oportuna solicitud de antecedentes a este Centro. ${ }^{19}$

18 «nformes nacionales con carácter socio-político emitidos quincenalmente por el Servicio de Información de la Dirección General de Seguridad y la Brigada de Información Policial de Alicante» (12 sept. 1947), Gobierno Civil, Secretaría General, GC-Go2573.001, Archivo Histórico Provincial de Alicante.

19 «Sobre individuos detenidos por sospechosos e indocumentados» (31 may. 1946), Gobierno Civil, Secretaría General, GC-GO3478.001, Archivo Histórico Provincial de Alicante. Es cuantiosa la documentación ubicada en este archivo respecto a la preocupación por los movimientos de personas que escapaban de las exigencias administrativas de la dictadura, especialmente con aquellos que se encontraban en régimen de libertad vigilada y pudieran proceder de otras provincias. Una documentación que, por otra parte, es vital para el conocimiento de las estrategias utilizadas por los migrantes para escapar de los controles del Régimen y, también, para el estudio de las dificultades que tuvo la dictadura en implantarlos. Algunos ejemplos en: «Sobre zonas de rojos huidos» (25 abr. 
Desde el mismo Día de la Victoria, el salvoconducto, que era obligatorio desde 1939, se convirtió en el documento imprescindible para realizar cualquier tipo de movimiento dentro de las fronteras del Estado español. ${ }^{20} \mathrm{Su}$ finalidad fue controlar los movimientos y actividades de aquellos que pretendieran desplazarse entre las distintas provincias españolas. Un requisito imprescindible, aunque los migrantes dispusieran de otros medios de identificación:

Confirmo a V.E mi telegrama actual, que afecta a la Tarjeta de Identidad que expide la Guardia Civil en determinadas zonas y provincias; y a este efecto, debo participarle que el citado documento no exceptúa a sus poseedores de proveerse de salvoconducto ordinario, ya que la Tarjeta de Identidad tiene fines de identificación y el salvoconducto de control de movimiento y actividades de ciudadanos. ${ }^{21}$

Como podemos ver, una maraña de trabas identificativas fue conformada por la dictadura con el único fin de someter a la población a un control exhaustivo de todos sus movimientos y actividades. Un entramado que no acabaría simplificándose en un solo documento hasta la implantación, a mediados de la década de los cincuenta, del documento nacional de identidad (MARín CORBERA 2010b). Pero hasta ese momento, la percepción y las quejas de la población respecto a este entramado burocrático se centraron en los fines recaudatorios de la dictadura, ya que la expedición de toda la documentación mencionada llevó aparejada una imposición fiscal que incluyó, dentro del gasto económico que conlleva toda emigración, una especie de «tasa migratoria» para realizar el desplazamiento, incluso dentro del territorio español:

1944), Archivo Histórico Provincial de Alicante, Gobierno Civil, Secretaría General, GC-Go3473.001; $\mathrm{y}$ «Comunicado del Director General de Seguridad sobre numerosos desconocidos por viajar sin salvoconducto» (16 may. 1944), Gobierno Civil, Secretaría General, GC-Go3473.001, Archivo Histórico Provincial de Alicante.

20 «Orden Circular de 2 de junio de 1939 dictando normas para la ejecución de la censura postal y telegráfica, censura de Prensa y expedición de salvoconductos», BOE (4 junio 1939): 3052.

21 «Dirección General de Seguridad: Sobre la Tarjeta de Identidad, expedida por la Guardia Civil, la cual no exceptúa de proveerse de salvoconducto» (28 en. 1948), Gobierno Civil, Secretaría General, GC-GO3478.001, Archivo Histórico Provincial de Alicante.

FRANQUISME \& TRANSICIÓ 4 (2016) ISSN 2014-511X PUNCTUM, UNIVERSITAT OBERTA DE CATALUNYA \& FUNDACIÓ CARLES PI I SUNYER 
Salvoconductos: Nuevamente se han producido comentarios de censura sobre la persistencia del régimen de salvoconductos; citándose casos de personas que, pese a ir suficientemente documentadas, sufren imposición de multas en sus desplazamientos fuera de la provincia, por carecer del referido documento; a este respecto se pone de relieve que, el único fin que persigue el Gobierno, es el de mantener este impuesto, ya que tal documento se considera nulo a efectos de identificación. ${ }^{22}$

Se trata de un cúmulo de dificultades que no terminaron con el traslado al lugar escogido para desarrollar una nueva vida. Estas dificultades continuaron durante los primeros momentos de la instalación en la capital catalana, llegando incluso a no producirse el asentamiento definitivo en la primera tentativa.

\subsection{El asentamiento en Barcelona y el mantenimiento de los canales comunicativos con los lugares de origen}

Todos los testimonios utilizados para este trabajo, y que realizaron el viaje en ferrocarril, mencionan y recuerdan los controles que la Guardia Urbana de Barcelona ejerció sobre los recién llegados a la capital catalana. Todos salvo uno, curiosamente el que arribó a la ciudad en primer lugar:

En aquellos momentos nadie te molestaba cuando bajabas del tren, no como en años posteriores, en donde habían puesto policía para que la gente no tuviera facilidades a la hora de querer venir aquí. No te molestaban, pero las estaciones estaban llenas de soldados, de guardias civiles y policía patrullando por toda la estación. Era una ciudad tomada, Barcelona era una ciudad tomada en el año $1940 .{ }^{23}$

22 «Informes nacionales con carácter socio-político emitidos quincenalmente por el Servicio de Información de la Dirección General de Seguridad y la Brigada de Información Policial de Alicante» (22 may. 1947), Gobierno Civil, Secretaría General, GC-Go2573.001, Archivo Histórico Provincial de Alicante.

23 Entrevista realizada a Arnaldo Tovar Muñoz (7 de noviembre de 2014). 
En lo que coinciden todos los testimonios es en la mención de algún familiar asentado en Barcelona con anterioridad a la Guerra Civil prestando ayuda en los primeros meses de residencia. Y de nuevo, la coincidencia se ubica en la importancia de las mujeres, ya que los seis testimonios utilizados para este trabajo atribuyen a una mujer, ya fuera de la propia familia o ajena a ella, el principal papel en esos primeros meses de instalación en la capital catalana:

Cuando nosotros llegamos aquí estaba la madre de mi padre, mi abuela. También estaban mis tías. Vivían todas en la Barceloneta. Mi madre, no sé por qué circunstancias, cuando llegamos, fuimos a vivir a casa de una amiga suya que también era viuda de la guerra. Su marido era muy amigo de mi padre. Mi madre fue a visitar a mi abuela y a mis tías, todas se alegraron mucho. Mi madre nos llevaba a casa de mi abuela a comer o a almorzar, estábamos allí hasta la tarde que ella llegaba y nos íbamos al piso de la amiga de mi madre. A las dos semanas de llegar mi madre consiguió un piso en la Barceloneta, en el mismo barrio en donde vivía mi abuela. Mi abuela y mis tías ya estaban en Barcelona antes de la guerra. Mis tías vinieron primero en el año 193001931. Y durante la guerra, en el año 1938 trajeron a mi abuela. ${ }^{24}$

Es obvio que también tuvieron que hacer frente, al igual que en sus pueblos de origen, a los rigores de una posguerra que fue especialmente dura también en los ámbitos urbanos:

Nosotros teníamos en Barcelona una hermana de mi madre, una tía mía que estaba casada con un carpintero [...] este le dijo a mi padre que nos viniéramos a Barcelona ya que mi padre no conseguía encontrar un trabajo normal. Nos instalamos en casa de mi tía, todo muy bien, muy atentos; pero claro, mi padre no conseguía encontrar trabajo aquí en Barcelona. Claro, la familia de mi madre ya estaba algo cansada de que mi padre no encontrara trabajo. Mi padre volvió a irse otra vez a Cartagena para ver si allí volvía a encontrar trabajo, pero nada. Al poco tiempo tuvo que volverse a Barcelona porque allí 
tampoco encontraba nada, un desastre, los primeros meses o años fueron una calamidad. ${ }^{25}$

Las dificultades se amplificaban en el caso de las mujeres que no podían acreditar su viudedad, sobre todo aquellas que tenían a sus maridos en el exilio:

A San Andrés nos fuimos en 1946. Llegamos allí por mediación de mi tía Agueda. Su marido tenía una hermana que estaba casada con un catalán: Fernando se llamaba. Aquí no les daban los pisos a las mujeres, solo a las viudas, solo se los daban a los cabeza de familia, solo a los hombres les daban el contrato de alquiler, a las mujeres no. Mi madre, como no era viuda, ya que mi padre aparecía como desaparecido, no podía justificar por ningún sitio [...]; mi madre y todos ahí llorando: «Fernando, por lo que más quiera hable usted con su padre». Habló con su padre y mira, al día siguiente vino con el contrato. ${ }^{26}$

Pero estas dificultades pudieron hacer germinar un sentimiento de solidaridad y empatía entre estas primeras migrantes que, años más tarde, derivó hacia una marcada importancia de las mujeres en la continuación de las cadenas migratorias que comunicaron Murcia con Barcelona. Fue especialmente palpable entre aquellas mujeres que abandonaron sus localidades de origen para trabajar en el servicio doméstico en las grandes ciudades (SÁENZ DEL CASTILlo 2016); una vía de análisis que aún está por desarrollar en el estudio de las migraciones interiores de la posguerra:

Mi madre, yo me acuerdo, cuando cogimos la casa en San Andrés, una gran cantidad de mujeres de Águilas, que conocían a mi tía allí en el pueblo y esta nos iba diciendo donde estaban y cuando llegaban cada una; y como cuando llegabas aquí no te dejaban entrar sin el salvoconducto, mi madre y yo íbamos con la cédula y nos las llevábamos como si fueran familia, las teníamos dos o tres días en casa y les buscábamos un sitio para servir, como conocía-

25 Entrevista realizada a Fernando Martínez (10 de noviembre de 2014).

26 Entrevista realizada a Juan Navarro García (11 de noviembre de 2014). 
mos a tanta gente, siempre por una o por otra lográbamos encontrarles trabajo en alguna casa. ${ }^{27}$

La primera en venir fue mi hermana mayor. Vino para servir en una casa en 1949. A ella le encontró el trabajo una prima nuestra del pueblo que vino un par de años antes, y que, por cierto, fue la que me acogió durante tres años cuando yo llegué a Barcelona. Esta prima nuestra fue la que inició la llegada escalonada de todas mis hermanas, todas para servir en la misma casa. Y después, mi hermana mayor fue la que me buscó trabajo a mí en un bar. Yo cuando llegué prácticamente lo tenía todo preparado por mi hermana. ${ }^{28}$

Mi padre ya había residido en Barcelona durante los años treinta. Esto le valió para conocer a gente. Gracias a esto, una tía mía, hermana de mi padre, consiguió un trabajo como sirvienta en la casa del propietario del Teatro Comedia, no sé, debió de ser a mediados de los cuarenta, ya que mi padre vino la segunda vez en 1949. Pues bien, mi tía devolvió el favor e intercedió para que mi padre fuera contratado de tramoyista en el teatro. Mi padre pasó unas semanas aquí y cuando vio que el trabajo era algo estable, mi madre se vino aquí con él. ${ }^{29}$

Pero no todas las historias de vida inmiscuidas en este proceso migratorio tuvieron un final feliz. Las dificultades de la posguerra en las grandes ciudades también influyeron poderosamente para que muchas trayectorias cargadas de deseos destinados a construir una vida mejor fuera de sus comunidades de origen no se produjeran del modo deseado. Estos relatos son muy difíciles de conseguir a través de las fuentes orales, ya que, en cierta medida, siempre suelen acabar conformando una memoria de «éxito» respecto a los propósitos que sus padres se habían marcado inicialmente. Por el contrario, en los archivos sí se podría acometer una labor destinada a rescatar esas voces olvidadas que, en su experiencia emigratoria, tuvieron que solicitar ayuda a las autoridades guberna-

27 Ibídem.

28 Entrevista realizada a José Sánchez González (4 de noviembre de 2014).

29 Entrevista realizada a José Molina Ayala (3o de octubre de 2014). 
tivas de la dictadura, que llegaron incluso a justificarse por una serie de «pecados» vinculados a la guerra o a la simple iniciativa de probar fortuna en la capital catalana:

Barcelona 29 de abril de 1942. Excmo. Sr.: Empiezo pidiéndole perdón por el atrevimiento de dirigirme a V.E., pero me encuentro tan apurada y ya sin fuerzas para arrastrar esta pesada cruz por el pedregoso calvario de la vida. Soy de Lorca [...] Una servidora que tuvo la desgracia de perder a su marido con los rojos [...] Me coloqué con las Hermanas de la Caridad y con ellas he permanecido dos años trabajando pero por falta de algodón y oro había tan poco trabajo que como veían mi situación tan apurada me dieron una carta que le acompaño para ver si esta me colocaba con ellas y por la misma quedará V.E. enterado de la razón por la que estoy en Barcelona acompañada de mi hija [...] Cuando me presenté con la baja del racionamiento de mi pueblo de procedencia no conseguí el racionamiento aquí y ya llevo próximo a dos meses sin saber cuál es el pan que Dios nos dice «El pan nuestro de cada día». Y esto es lo único que le pide y desea esta pobre viuda. ${ }^{30}$

\section{Conclusiones}

Lo expuesto en este trabajo es un acercamiento a una labor que desde hace algunos años se insiste en que debe ser abordada con mayor intensidad por parte de la historiografía. Es cierto que en los últimos años se han dado avances extraordinarios respecto a los planteamientos teóricos y metodológicos destinados a dar respuesta a las preguntas que nos ofrece este fenómeno migratorio tan complejo que, por otra parte, y desde hace más de medio siglo (DE Bolos 1959), la estadística nos evidencia que fue más importante de lo que hasta el momento se había pensado.

Pero no por ello debemos dejar de lado el enriquecimiento del debate con la aportación de nuevas preguntas y el medio para darles respuesta. Un ejemplo es la necesidad de estudiar el fenómeno desde diferentes perspectivas analíticas, mediante la interrelación de los territorios

30 Fondo Habilitación, Negociado 11-2, caja 1, carpeta «Varios», Archivo Histórico de la Delegación del Gobierno en Cataluña (Archivo Histórico del Gobierno Civil de Barcelona). 
emigratorios, los inmigratorios y los ubicados entre ambos, con el fin de acercarnos mejor a las condiciones y dificultades que hubieron de afrontar los migrantes en el traslado.

La combinación de fuentes de todo tipo, sin priorizar unas sobre otras, nos ayudaría a realizar un descenso desde las interpretaciones macro a las micro sin excesivas dificultades a través del planteamiento teóricometodológico que nos proporciona la teoría de redes migratorias; para ello, la combinación de las fuentes estadísticas ligadas a la demografía, la documentación archivística generada por el nuevo Estado y las fuentes orales, nos permitiría construir un relato sobre las migraciones desarrolladas durante la inmediata posguerra en donde tendrían cabida las cifras del fenómeno, el comportamiento del Régimen franquista respecto a estas migraciones y las experiencias individuales de los migrantes. Combinación que, pensamos, nos ayudaría a una mejor comprensión y a un enriquecimiento del debate ligado a estas migraciones «olvidadas» dentro de la cronología general del franquismo.

Y por último, también nos gustaría insistir en la necesidad de realizar, o continuar en algunos casos, el estudio en otras grandes ciudades del Estado español, especialmente en las áreas metropolitanas de Madrid (SILVESTRE 2015) y Valencia, ya que sería de vital importancia para realizar las convenientes comparativas analíticas con el fin de intentar dilucidar la verdadera intensidad del fenómeno migratorio desarrollado en la inmediata posguerra.

\section{Bibliografía}

AlCAIDE INCHAUSTI, J. coord. 2007. Evolución de la población española en el siglo Xx por provincias y comunidades autónomas, 2 vol. Bilbao: Fundación BBVA.

BeL Adell, M. 1982. Población y recursos humanos de la Región de Murcia. Murcia: Editora Regional Murciana.

BORDERÍAs, C. 1993. «Emigración y trayectorias sociales femeninas». Historia Social 17: 75-94.

BORDETAS, I. 2009. «El viatge: canals d'informació, rutes, condicions i arribada». En Martí Marín Corbera, dir., Memòries del viatge, 1940-1975. Sant Adrià de Besòs: Museu d'Història de la Immigració a Catalunya.

BотеY, J. 1986. Cinquanta-quatre relats d'immigració. Barcelona: Centre d’Estudis de l'Hospitalet de Llobregat / Diputació de Barcelona. 
CABRÉ, A., i I. PUjADES. 1989. «La població: immigració i explosió demogràfica». En J. NADAL et al., dir., Història econòmica de la Catalunya contemporània, vol. 5, 11-128. Barcelona: Enciclopèdia Catalana.

CAPEL, H. 1963. La población y los movimientos migratorios en el municipio de Lorca (Murcia). Murcia: Universidad de Murcia.

Carrasco, J. 1994. Verdúm. Desde el año 1952. Barcelona: Associació de Veïns de Verdúm.

De Bolos, M. 1959. «La inmigración en Barcelona en los dos últimos decenios». Estudios Geográficos 75: 209-249.

De Silva, J. 1978. Nosotros los evacuados. Barcelona: Plaza \& Janés Editores.

ECHeniQue, M. 1965. «El barraquismo en Montjüic». Tesis doctoral, Escuela Técnica Superior de Arquitectura de Barcelona.

ESCUDERO, F. 200o. Lo cuentan como lo han vivido (República, guerra y represión en Murcia). Murcia: Universidad de Murcia.

- 2007. Dictadura y oposición al franquismo en Murcia. Murcia: Universidad de Murcia / Editora Regional de Murcia.

FERnÁndez Gómez, J.A. 2004. Buscando el pan y el trabajo. Sobre la industrialización franquista y sus costes sociales en Villaverde (Madrid) 1940-1965. Madrid: Miño y Dávila.

Fontes, L. 1946. «Barcelona, hermana mayor de Murcia». La Vanguardia, 7 mayo, 2.

GARCía ABAD, R. 2001. «El establecimiento de redes migratorias: una propuesta metodológica para descubrirlas y medir su importancia en los procesos migratorios». IV Congreso de la Asociación de Demografía Histórica (Castelo Branco Abril 2001). http://pendientedemigracion.ucm.es/info/adeh/VI_Congreso/ Paralela11.html.

GARCÍA BARBANCHO, A. 1967. Las migraciones interiores españolas. Estudio cuantitativo desde 19oo. Madrid: Estudios del Instituto de Desarrollo Económico.

Gómez Bravo, G. 2009. El exilio interior. Cárcel y represión en la España franquista (1939-1950). Madrid: Taurus / Santillana.

GonZÁlez, C., F. Escudero y J. ANdúJAR. 2015. El naufragio de la humanidad. Republicanos españoles y murcianos en los campos de concentración. Valencia: Editorial Enkuadres.

Guldi, J., y D. ArmitaGe. 2016. Manifiesto por la Historia. Madrid: Alianza Editorial.

GURAK, D., y F. CACES, 1998. «Redes migratorias y la formación de sistemas de migración». En G. MALGESINI, coord., Cruzando fronteras: migraciones en el sistema mundial, 75-110. Barcelona: Icaria / Fundación Hogar del Empleado.

Hirsch, M. 1997. Family Frames. Photography narrative and Postmemory. Cambridge: Harvard University Press.

Marín Corbera, M. 2004. D’immigrants a ciutadans. La immigració a Catalunya, del franquisme a la recuperació de la democràcia. Sant Adrià del Besòs: Museu d'Història de la Immigració de Catalunya.

—. 2005a. «Ritmes i composició migratoris. Les xifres d'un fenomen complex». L’Avenç 298: 24-31. 
Marín Corbera, M. 2005b. «Orígens de l'emigració de postguerra a Sabadell, 19391960». Arraona 28: 24-35.

- 2006. «Franquismo e inmigración interior: el caso de Sabadell (1939-1960)». Historia Social 17: 131-151.

— . 2010a. «Entre el dret de fuga i la invasió pacífica: prejudicis, polítiques i realitats de la immigració a Catalunya durant el franquisme». Recerques: Història, Economia $i$ Cultura 58-59: 127-149.

_ 2010b. «La gestación del Documento Nacional de Identidad: Un proyecto de control totalitario para la España Franquista». En C. NAVAJAs y D. ITUR RIAGA, coord., Novísima: II Congreso Internacional de Nuestro Tiempo, 323-338. Logroño: Universidad de La Rioja.

MARín Gómez, I. 2003. El laurel y la retama en la memoria. Tiempo de posguerra en Murcia, 1939-1952. Universidad de Murcia.

Marín Jover, J.M. 1987. Prisión y clandestinidad bajo el franquismo. Murcia: Novograf. Martínez Carrión, J.M. 2002. Historia económica de la Región de Murcia. Siglos XIX y $X X$. Murcia: Editora Regional Murciana.

— 2005. «En busca del bienestar: las migraciones en la Historia de la Región de Murcia». En A. Pedreño y M. Hernández, coord., La condición inmigrante: explicaciones e investigaciones desde la Región de Murcia, 33-6o. Universidad de Murcia.

Martínez Ovejero, A. 2015. «Peligrosos e indeseables para la Causa Nacional. Los vencidos de la Guerra Civil en la Región de Murcia, 1939-1948. Una visión regional con proyección nacional». Tesis doctoral, Universidad de Murcia. http://hdl.handle. net $/ 10201 / 48298$.

MARTínez Soto, A.P., et al. 20o8. «Itinerarios migratorios y mercados de trabajo en la minería meridional del siglo XIX». Boletín Geológico y Minero 119, 3: 399-418.

MAteOS, J. 1990. Murcianos en Cataluña. Barcelona: E.C.O. S.A.

-1993. De Lorca a Barcelona. Barcelona: E.C.O. S.A.

Molina, J. 2012. Detrás del muro. Viaje al interior de una memoria. Barcelona: Grafein Ediciones.

Molinero, C., M. Sala y J. Sobrequés, ed. 2003. Una inmensa prisión. Los campos de concentración y las prisiones durante la guerra civil y el franquismo. Barcelona: Crítica.

Morata, A. 2008. La población de Águilas y su evolución. Siglos XVIII-XX. Murcia: Ayuntamiento de Águilas.

NiColÁs MARín, M.E. 1988. «La violencia política del franquismo en un espacio rural murciano: la persistencia del sistema de dominación». En Siro Luis Villas et al. Homenatge al doctor Sebastià García Martínez, vol. 3, 447-461. Valencia: Generalitat Valenciana / Universitat de València.

Prada Rodríguez, J. 2010. La España masacrada. La represión franquista de guerra y posguerra. Madrid: Alianza Editorial.

Puig, A. 1991. «De Pedro Martínez a Sabadell: l'emigració, una realitat no exclusivament econòmica, 1920-1975». Tesis doctoral, Universitat Autònoma de Barcelona. 
PUYOL, R. 1979. Emigración y desigualdades regionales en España. Madrid: Editorial Magisterio Español.

Quílez Esteve, L. 2014. «Hacia una teoría de la posmemoria. Reflexiones en torno a las representaciones de la memoria generacional». Historiografias: Revista de Historia y Teoría 8: 57-75. http://www.unizar.es/historiografias/numeros/8/quilez.pdf.

Oyón, J.L., y B. IGLESIAS. 2010. «Les barraques i l’infrahabitatge en la construcció de Barcelona, 1914-1950». En M. TATJER y C. LARrea, ed., Barraques. La Barcelona informal del segle $\mathrm{XX}$. Barcelona: Ajuntament de Barcelona.

OYón, J.L., J. MALDONADO y E. GRIFUL. 2001. Barcelona 1930: un atlas social. Barcelona: Edicions de la Universitat Politècnica de Catalunya.

SÁenz del Castillo, A. 2016. «En el limbo. El servicio doméstico durante el franquismo en España». Historia Social 84: 77-92.

SARLO, B. 2005. Tiempo pasado. Cultura de la memoria y giro subjetivo. Una discusión. Buenos Aires: Siglo XXI.

Silvestre, J. 2015. «The occupational mobility of rural-urban migrants: Madrid in the 1950's». Historia Agraria. Revista de Agricultura e Historia Rural 67: 143-178.

SUDRIÀ, C. 1994. «L'economia catalana en els anys d'entreguerres: consolidació industrial i diversificació productiva». J. NADAL et al., dir., Història econòmica de la Catalunya contemporània, vol. 4, 25-97. Barcelona: Enciclopèdia Catalana.

TÉBAR, J., et al. 2015. Gobernadores. Barcelona en la España franquista (1939-1977). Granada: Editorial Comares.

Tierno Galván, E. 1982. Cabos sueltos. Barcelona: Bruguera.

TUDELA, E. 2015. «Marcharse lejos: la emigración granadina a Barcelona en la posguerra». En P. Folguera et al., coord., Pensar con la Historia desde el siglo XXI. Actas del XII Congreso de la Asociación de Historia Contemporánea, 5841-5862. Madrid: Universidad Autónoma de Madrid.

Vilanova, M. 1996. Las mayorías invisibles: explotación fabril y represión: 26 entrevistas. Barcelona: Icaria.

VILAR, J.B. 2008. «El exilio español de 1939 en el Norte de África». Historia del Presente 12: $19-42$.

VILAR, J.B., et al. 1999. Las emigraciones murcianas contemporáneas. Universidad de Murcia.

Vilar, J.B., y P.M. EgEA. 1989. La minería murciana contemporánea (1840-1930). Murcia: Cajamurcia / Universidad de Murcia.

YsÀs, P., y C. MOLINERo. 1987. «La població catalana a la post-guerra: creixement i concentració, 1939-1950». L’Avenç 102: 38-46. 